\title{
New kid on the block
}

\author{
As Editor of the Journal of Clinical Investigation, I am pleased to announce \\ the January 2016 launch of JCI Insight, which will publish well-executed, \\ high-quality research across biomedicine that presents a focused yet \\ insightful line of investigation. The new journal, published under an open- \\ access model, represents an expansion of the American Society for Clinical \\ Investigation's longstanding commitment to disseminating preclinical, \\ translational, and early-phase clinical research that has the potential to \\ advance the practice of medicine. JCI Insight will be the second Society \\ publication since the $\mathrm{JCl}$ was founded in 1924.
}

In 1924, Alfred Cohn articulated that the mission of the American Society for Clinical Investigation is to "contribute to an increase in knowledge" (1). And it was in that spirit that the Journal of Clinical Investigation was born. While the JCI has been the flagship journal of our Society, and a paragon of excellence in biomedical research, many terrific papers submitted to the JCI do not end up being published in the Journal. Accordingly, in keeping with the original mandate of the Society, I am pleased to announce the January 2016 launch of a new journal called JCI Insight.

At the JCI we have a tradition of publishing studies that are comprehensive in their investigation of mechanistic detail. In essence, the papers we publish are distinguished by a unique "JCI personality." In my inaugural editorial nearly four years ago, I reflected that a JCI paper should be "rigorous and comprehensive so that it moves the field forward, creates new knowledge, reveals new mechanisms, and advances our understanding of the biology of disease and/or treatment" (2). And, in fact, of the nearly 13,000 papers that have since crossed our desks, we have published many such beautiful papers. However, we publish only a small percentage of the manuscripts submitted, and I had to ask myself about the fate of the many papers that we have not published. In my review of our internal manuscript tracking data, it became apparent that many of the papers we did not publish were indeed excellent and impactful biomedical studies that changed the thinking in the field and often showed potential for clinical translation. As I reflected on why we did not publish these very insightful papers, I realized that they had a different "personality." Many of these studies provided new advances that spurred subsequent research in the field but were more discreet in scope. It was disheartening for me, as Editor of a journal dedicated to publishing high-quality mechanistic-based biomedical research, to learn that we are telling authors of these many meritorious and excellent papers to go elsewhere. Having served for more than three years at the helm of the JCI, it became obvious to me what needed to happen: provide another venue for our ASCI members, and the JCI community, to publish their high-impact work - hence the launch of JCI Insight.

So, you may ask, what kind of journal will JCI Insight be? Its mission will be to publish well-executed, high-quality, insightful research in all disciplines of medicine. The primary distinction between JCI and JCI Insight is that articles published in JCI Insight will be from a more focused line of investigation. For example, a JCI Insight paper might report a fascinating new phenotype in a preclinical model or novel observations in a clinical study without a full exploration of the underlying mechanism. Moreover, repeated rounds of revisions and requests for excessive experimentation will be held to a minimum or avoided altogether.

Initially, I will serve as Editor in Chief so as to be able to fully coordinate the launch with our flagship journal, the JCI. Manu- scripts will be adjudicated by a team of experienced professional editors, including Sarah Jackson, Jillian Hurst, and Corinne Williams. A consulting editorial board of experts, largely made up of active members of the Society, will aid us in the peer review of submitted papers. In addition to considering direct submissions, authors who have had manuscripts externally reviewed at the JCI that we believe are more suited to JCI Insight will be invited to have their work considered at JCI Insight without rereview. In some cases, we will not ask for new experiments but will ask for a focused rewrite of the text and efforts to enhance figure presentation. In one and a half years, the JCI editorship leaves its current affiliation (Duke University, University of North Carolina, Duke-NUS, and Sanford-Burnham Medical Research Institute), as stipulated by the Society's constitution. However, JCI Insight will remain at the current site, where we can continue to direct its course, allowing the future JCI Editor (and his/her editorial board) to concentrate solely on publishing the JCI. Manuscripts submitted to the JCI will continue to be handled by the JCI's distinguished Editorial Board, and decisions at the JCI will be made independently of JCI Insight. Just as in the JCI, all research articles published in JCI Insight will be freely available from the time of publication.

We welcome submissions from all authors working in biomedical research, and while there will be no requirement for affiliation with the ASCI, active ASCI members will be granted three guaranteed external reviews per year for manuscripts that fit the scope of JCI Insight. It is my intent to streamline the peer review so that it is both rapid and fair. Requests for excessive additional experimentation will be discouraged; however, only rigorous and technically wellconducted science will be published. The JCI brand stands for excellence, and this is something on which I will not compromise.

Additionally, JCI Insight will enhance the financial sustainability of our Society. In 1996, then JCI Editor Ajit Varki, and the ASCI Council, decided that all research published in the JCI belonged in the public domain free of charge (3). We are immensely proud to have helped to herald the era of free and open access to research. 
Now, 20 years later, the research community has seen widespread adoption of the open-access publication model. JCI covers the costs of publication and supports the activities of the ASCI through author publication and other charges. By expanding our publication base with JCI Insight, we believe we can provide long-term financial security to the Society and also publish the many impactful papers that we receive from the JCI community of scientists. As a nonprofit organization whose mission is to benefit the scientific community, the
Society is immensely proud to have been at the forefront of demonstrating that this approach can work.

We look forward to serving our community of investigators with a new platform to disseminate their research ideas and discoveries. We believe that our future is bright and that we can continue the legacy created over 90 years ago by our Society.

As always, I welcome your thoughts and comments, and I encourage you to learn more details about JCI Insight by visiting www.insight.jci.org.
It is a continuing honor and privilege to serve the JCI and the ASCI community.

\section{Howard A. Rockman \\ Editor in Chief \\ The Journal of Clinical Investigation}

1. Cohn AE. Purposes in medical research: an introduction to the Journal of Clinical Investigation. JClin Invest. 1924;1(1):1-11.

2. Rockman HA. Tradition, tradition. JClin Invest. 2012;122(3):785-786

3. Varki AP. The times they are still a'changing: keeping up with the times. JClin Invest. 1996;97(1):1. 